\title{
西藏特有植物砂生槐天然居群遗传多样性研究
}

\author{
赵阿曼 ${ }^{1} \quad$ 刘志民 $^{2 *} \quad$ 康向阳 $^{1} \quad$ 周世良 $^{3}$ \\ 1 ( 北京林业大学生物科学与技术学院, 北京 100083) \\ 2 (中国科学院沈阳应用生态研究所, 沈阳 110016) \\ 3 (中国科学院植物研究所系统与进化植物学重点实验室, 北京 100093)
}

摘要: 采用等位酶淀粉凝胶电泳技术对西藏雅鲁藏布江中游砂生槐( Sophora moorcroftiana) 10 个天然居群的遗传 多样性进行了研究。13 个酶系统 24 个酶位点 (46 个等位基因) 的检测结果表明, 砂生槐具较低的遗传变异水平。 居群水平上的遗传多样性指标分别为: 多态位点百分率 $P_{p}=25.0 \% \sim 37.5 \%$, 等位基因平均数 $A_{p}=1.3 \sim 1.7$, 平均 期望杂合度 $H_{e p}=0.112 \sim 0.169$ 种水平上的遗传多样性 $\left(P_{s}=37.5 \%, A_{s}=1.9, H_{e s}=0.171\right)$ 低于长寿命木本被子 植物的平均值 $\left(P_{s}=59.5 \%, A_{s}=2.10, H_{e s}=0.183\right)$ 。居群遗传结构的分析显示, 10 个居群中随机交配的偏差为 $F_{I S}=-0.0071$, 表明砂生槐在居群水平上存在轻微的杂合子过量现象, 偏离了 Hardy-Weinberg 平衡; $F_{S T}=0.1748$, 表明砂生槐是居群间分化较大的一类多年生木本植物, 主要原因是环境恶化和人类活动干扰 (过度砍伐、放牧等) 导致其生境片断化，从而影响了居群间基因交流而造成基因流水平较低 $(N m=1.1802)$ 。砂生槐高海拔居群 $\mathrm{H} 2$ (谢通门)、H31 (江当 1)、H32 (江当 2)、H5 (朗塞岭) 包含着绝大部分等位基因, 显示了相对较高的遗传多样性水 平, 应加以保护和管理, 作为砂生槐种质资源就地保存的基地。

关键词：西藏，砂生槐，等位酶，遗传多样性，遗传分化

中图分类号:Q16,Q347文献标识码: A 文章编号 : 1005-0094(2003)02-0091-09

\section{Allozyme variation in Sophora moorcroftiana, an endemic species of Tibet , China}

ZHAO A-Man ${ }^{1}$, LIU Zhi-Min ${ }^{2 *}$, KANG Xiang-Yang ${ }^{1}$, ZHOU Shi-Liang ${ }^{3}$

1 College of Biological Sciences and Technology, Beijing Forestry University , Beijing 100083

2 Institute of Applied Ecology, Chinese Academy of Sciences, Shenyang 110016

3 Laboratory of Systematic and Evolutionary Botany, Institute of Botany, Chinese Academy of Sciences , Beijing 100093

Abstract : The genetic diversity of ten populations of Sophora moorcroftiana in the middle reaches of the Yarlung Zangbo River, Tibet, China was assessed using allozyme analysis by horizontal sliceable starch gel electrophoresis. Twenty four loci (46 alleles) of 13 enzyme systems demonstrate low levels of genetic variation within populations, with the value of $P_{p}=25.0 \% \sim 37.5 \%, A_{p}=1.3 \sim 1.7$ and $H_{e p}=0.112 \sim 0.169$. At the species level, the genetic diversity of $S$. moocroftiana $\left(P_{s}=37.5 \%, A_{s}=1.9, H_{e s}=0.171\right)$ was lower than the mean value of angiosperms of long-lived woody species $\left(P_{s}=59.5 \%, A_{s}=2.10, H_{e s}=\right.$ $0.183)$. Wright's $F$ statistics analysis indicated that $F_{I S}$, a measure of the deviation from random mating within the 10 populations, was -0.0071 , suggesting deviation from Hardy-Weinberg equilibrium and a slight heteroygote excess in some populations. The higher level of differentiation $\left(F_{S T}=0.1748\right)$ among populations than those of other long-lived woody plants may result from habitat fragmentation and low levels of gene flow $(N m=1.1802)$ caused by environmental deterioration and human disturbance, including overfelling and over-grazing. It was worth noting that populations H2 (Xietongmen) , H31 (Jiangdang1) , H32 ( Jiangdang2) , and H5 (Langsailing) harbored the majority of alleles and had high levels of genetic diver- 
sity, suggesting that these populations in particular should be conserved in situ.

Key words : Tibet, Sophora moorcroftiana, allozyme, genetic diversity, genetic differentiation

遗传多样性是生物多样性的核心问题, 是生物 进化的本质(季维智，宿兵，1998）。一般而言,特有 种由于其居群小 (受瓶颈作用影响)、生境片段化或 强烈的定向选择等原因易形成遗传变异匮乏（Barrett \& Koho，1991) ,而遗传变异匮乏又会限制居群 的适应可塑性，反过来又成为特有种稀有的原因 (Holsinger \& Gottlieb，1991)。对特有种遗传多样 性和居群遗传结构的研究, 是揭示其进化历史和适 应潜力的基础,也是了解其居群生物学特性、进一步 探讨形成其特有的原因的第一步, 可以为制定科学 的保护和利用措施提供重要依据 ( Hamrick \& Godt， 1996 ; Ge et al. , 1997)。

砂生槐 (Sophora moorcroftiana) 又称西藏狼牙 刺,豆科槐属多年生耐旱矮灌木, 是青藏高原特有 种, 雅鲁藏布江干暖河谷灌丛的主要代表植物种, 也 是半固定沙地上的先锋灌丛植物, 集中分布于雅鲁 藏布江中游海拔高度大致为 $3100 \sim 4100 \mathrm{~m}$ 的加查 一拉孜段或则当一拉孜段的河谷、低山区 ${ }^{(1)}$ 。砂生 槐为二倍体，其核型为 $2 \mathrm{n}=2 \mathrm{x}=18=12 \mathrm{~m}(4 \mathrm{SAT})+$ $6 \mathrm{sm}$ (王善敏等, 1995)。目前,有关砂生槐的抗旱性 状、沙生适应性、种子库等方面已有较多的研究 (王 为义，1980;赵文智,1998;赵文智，刘志民，2002）， 而有关其遗传多样性水平却未见报道。本文采用等 位酶分析技术对雅鲁藏布江中游砂生槐天然居群进 行了系统研究, 旨在揭示砂生槐种群的遗传变异水 平及其规律, 以期为该特有种的保护与利用提供科 学依据。

\section{1 材料和方法}

\section{1 材料采集}

供试材料采集于 $29^{\circ} \mathrm{E}, 88^{\circ} \sim 94^{\circ} \mathrm{N}$ 之间的雅鲁 藏布江中游河谷 (萨迦卡萨至八一镇), 海拔跨度为 $2947 \mathrm{~m}$ (八一镇的 $\mathrm{H} 8$ 居群 ) $4100 \mathrm{~m}$ (萨迦卡萨的 $\mathrm{H} 1$ 居群) , 基本上覆盖了砂生槐分布区 (图 1)。种 子收集于 10 个砂生槐天然居群，每个居群内随机设 置 5 块样地, 每块样地面积 $10 \mathrm{~m} \times 10 \mathrm{~m}$, 间隔约 500 $\sim 1000 \mathrm{~m}$; 在每个样地内随机布设 30 个 $20 \mathrm{~cm} \times 20$ $\mathrm{cm}$ 的小样方，收集表层种子。每居群各样方所采收 的种子在完成种子库研究后（刘志民等,2002) ,将
各样方种子等数量充分混合, 随机取 150 粒种子用 浓硫酸处理 $30 \mathrm{~min}$, 使其打破休眠,待发芽子叶展 开后, 挑取 40 个生长健康、子叶饱满且发绿的幼苗 用于制样分析。

\section{2 等位酶分析}

将所选幼苗加 $0.2 \mathrm{ml}$ 研磨缓冲液, 在冰浴中分 别研磨提取。研磨选用 Tris 马来酸提取液 (Soltis et al. , 1983 ）,外加 1\% 的俆基乙醇，4\% 的聚乙烯基吡 咯烷酮 (PVP-40T)。以新华 $\amalg$ 号滤纸做 $2 \times 6 \mathrm{~mm}$ 沁子 ( wick), 放入研磨液中, 吸足提取液后存入 $-80^{\circ} \mathrm{C}$ 冰箱备用。

缓冲液系统参考周世良等 (1998) 配方,采用 3 个缓冲液系统篮选适宜的酶 (表 1)。所用水解淀粉 为美国 Sigma 公司产品(S-4501)，凝胶浓度为 $12 \%$ 。 水平切片淀粉凝胶电泳的方法见王中仁 (1996)。 AAT 的染色方法参考 Soltis et al. (1983) ,AMP 的染 色方法参考 Soltis \& Rieseberg (1986) ,其他酶均采 用胶染法，见王中仁(1996)。

\section{3 数据处理}

酶谱判读依据 Wendel \& Weeden（1989）与王 中仁 (1996) 的原则和方法。定义多态位点的标准 为最常见的等位基因出现的频率不大于 0.95 (王中 仁,1996)。居群水平 (下标为 $p$ ”) 和种水平 (下标 “ s”) 遗传多样性 (变异) 以多态位点百分率 $P$ ( percentage of polymorphic loci)、每个位点的平均等位基 因数 A (average number of alleles per locus) 以及平 均观察杂合度 $H_{o}$ ( average observed heterozygosity) 和 平均期望杂合度 $H_{e}$ ( average expected heterozygosity) 来度量。种内居群间遗传分化采用Wright (1978) 的 $F$-统计量法 $\left(1-F_{I S}\right) \times\left(1-F_{S T}\right)=\left(1-F_{I T}\right)$ 来度 量。采用等位基因频率杂合度的 $\chi^{2}$ 分析对 $F_{S T}$ 值偏 离 0 值的程度进行显著性检验 (Khasa，1994)。上 述各项参数计算均采用 BIOSYS-1 (Swofford \& Selander, 1989) 程序完成。另外根据 $F=1-H_{o} / H_{e}$ 计 算各居群固定指数 $(F)$ (Wright，1965），利用 Wright

(1) Liu Z-M (刘志民). 2001. Case Studies on Adaptations of Vegetation to Disturbance and Roles of Disturbance in Determining Vegetation Processes (植物适应干扰机制和干扰对植被过程影响的若干例证研究) Cold \& Arid Regions Environmental \& Engineering Research Institute , Chinese Academy of Sciences , PhD. Thesis ,24-39. (in Chinese) 


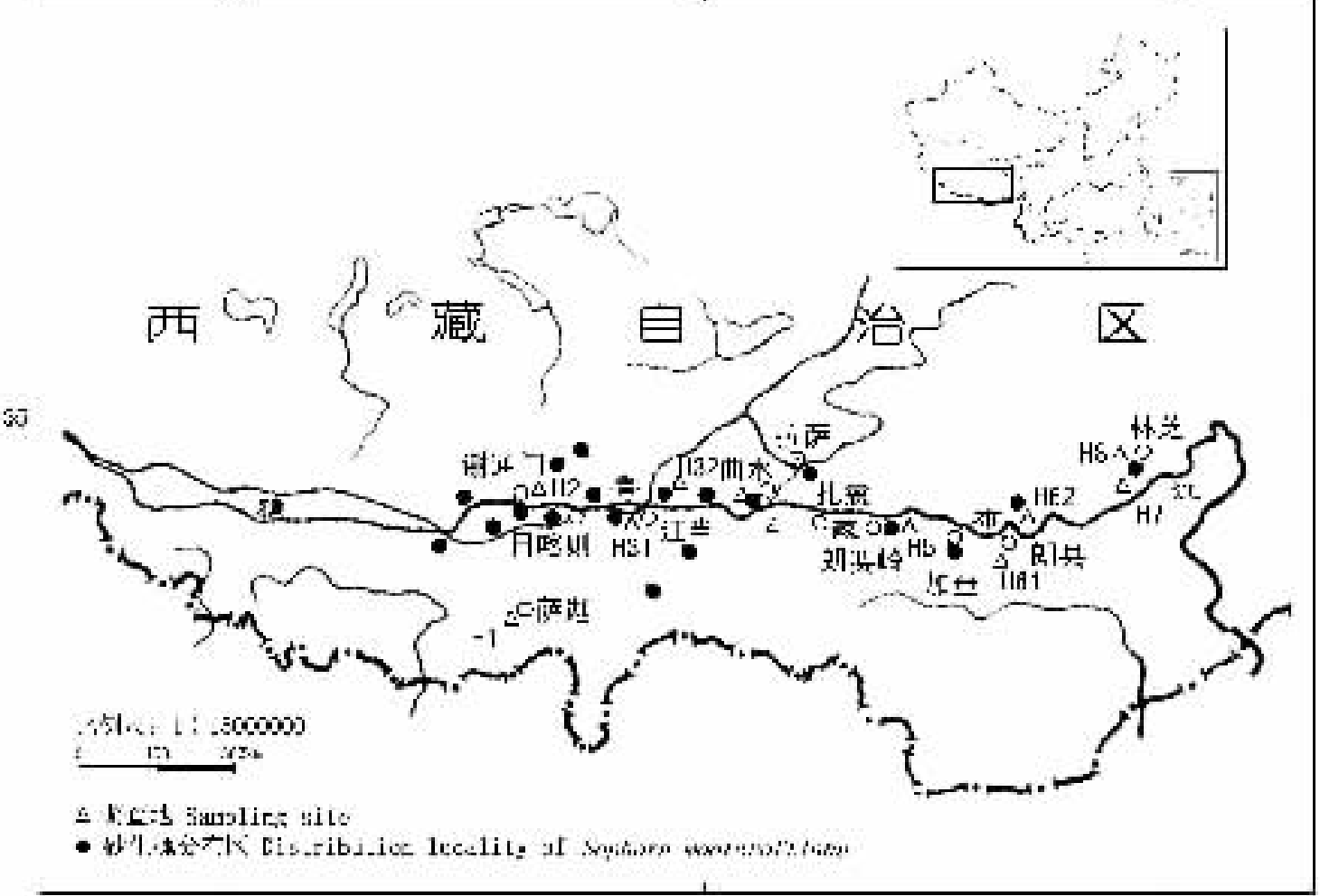

图 1 调查地位置和砂生槐分布图 ( $\triangle$ 代表采样居群)

$\mathrm{H} 1$ : 萨迦卡萨 ; H2 : 谢通门 $\left(29^{\circ} 20^{\prime} 03^{\prime \prime} \mathrm{N} ; 88^{\circ} 20^{\prime} 52^{\prime \prime} \mathrm{E}\right)$; H31 : 江当 1 ( $\left.29^{\circ} 20^{\prime} 14^{\prime \prime} \mathrm{N} ; 89^{\circ} 20^{\prime} 58^{\prime \prime} \mathrm{E}\right) ; \mathrm{H} 32$ : 江当 2 ( $\left.29^{\circ} 20^{\prime} 00^{\prime \prime} \mathrm{N} ; 89^{\circ} 21^{\prime} 00^{\prime \prime} \mathrm{E}\right)$; $\mathrm{H} 4$ : 曲水 $\left(29^{\circ} 16^{\prime} 38^{\prime \prime} \mathrm{N} ; 90^{\circ} 34^{\prime} 13^{\prime \prime} \mathrm{E}\right)$; H5 : 朗塞岭 $\left(29^{\circ} 15^{\prime} 36^{\prime \prime} \mathrm{N} ; 91^{\circ} 29^{\prime} 01^{\prime \prime} \mathrm{E}\right)$; H61 : 朗县 $1\left(^{\prime}\left(29^{\circ} 02^{\prime} 26^{\prime \prime} \mathrm{N} ; 9^{\circ} 03^{\prime} 06^{\prime \prime} \mathrm{E}\right)\right.$; H62 : 朗县 2 ( $29^{\circ}$ $\left.02^{\prime} 34^{\prime \prime} \mathrm{N} ; 93^{\circ} 02^{\prime} 49^{\prime \prime} \mathrm{E}\right) ; \mathrm{H} 7$ : 林芝 $\left(29^{\circ} 22^{\prime} 58^{\prime \prime} \mathrm{N} ; 94^{\circ} 24^{\prime} 58^{\prime \prime} \mathrm{E}\right) ; \mathrm{H} 8$ : 八一镇 $\left(29^{\circ} 22^{\prime} 57^{\prime \prime} \mathrm{N} ; 94^{\circ} 24^{\prime} 58^{\prime \prime} \mathrm{E}\right)$ 。

Fig. 1 Natural distribution of Sophora moorcroftiana and locations of the 10 populations collected. $\triangle$ represents sample populations.

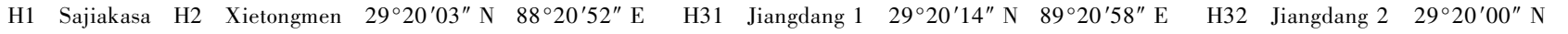
$\left.89^{\circ} 21^{\prime} 00^{\prime \prime} \mathrm{E}\right)$; H4 , Qushui $\left(29^{\circ} 16^{\prime} 38^{\prime \prime} \mathrm{N} ; 90^{\circ} 34^{\prime} 13^{\prime \prime} \mathrm{E}\right)$; H5 , Langsailing (29 $\left.15^{\prime} 36^{\prime \prime} \mathrm{N} ; 91^{\circ} 29^{\prime} 01^{\prime \prime} \mathrm{E}\right)$; H61 , Langxian 1 ( $29^{\circ} 02^{\prime} 26^{\prime \prime} \mathrm{N} ; 93^{\circ} 03^{\prime}$ $06^{\prime \prime}$ E) ; H62 , Langxian $2\left(29^{\circ} 02^{\prime} 34^{\prime \prime} \mathrm{N} ; 93^{\circ} 02^{\prime} 49^{\prime \prime} \mathrm{E}\right) ; \mathrm{H} 7$, Linzhi $\left(29^{\circ} 22^{\prime} 58^{\prime \prime} \mathrm{N} ; 94^{\circ} 24^{\prime} 58^{\prime \prime} \mathrm{E}\right)$; H8 , Bayizhen $\left(29^{\circ} 22^{\prime} 57^{\prime \prime} \mathrm{N} ; 94^{\circ} 24^{\prime} 58^{\prime \prime} \mathrm{E}\right)$ 。

表 1 分析的酶系统和对应的缓冲液系统以及每个酶系统检测到的位点数

Table 1 Enzyme systems assayed and relevant buffers , and loci detected in Sophora moorcroftiana

\begin{tabular}{|c|c|c|c|}
\hline $\begin{array}{c}\text { 酶系统 } \\
\text { Enzyme system }\end{array}$ & $\begin{array}{l}\text { EC 代号 } \\
\text { EC No. }{ }^{a}\end{array}$ & $\begin{array}{l}\text { 缓冲液系统 } \\
\text { Buffer system }\end{array}$ & $\begin{array}{l}\text { 位点数 } \\
\text { No. of loci }\end{array}$ \\
\hline 天冬氨酸转氨酶 Aspartate aminotransferase (AAT) & 2.6 .1 .1 & $\mathrm{~S}_{6}$ & 1 \\
\hline 乙醇脱氢酶 Alcohol dehydrogenase ( ADH) & 1.1 .1 .1 & $\mathrm{~S}_{1}$ & 1 \\
\hline 氨基肽酶 Aminopeptidase ( AMP) & 3.4 .11 .1 & $\mathrm{~S}_{6}$ & 2 \\
\hline 还原型辅酶 I 心肌黄酶 NAD (P) H-Diaphorase (DIA) & 1.6 .2 .2 & $\mathrm{~S}_{6}$ & 2 \\
\hline 果糖二磷酸醛缩酶 Fructose-bisphosphate aldolase (FBA) & 4.1 .2 .13 & $\mathrm{~S}_{1}$ & 1 \\
\hline 谷氨酸脱氢酶 Glutamate dehydrogenase (GDH) & 1.4 .1 .2 & $\mathrm{~S}_{1}$ & 1 \\
\hline 磷酸葡萄糖异构酶 Phosphoglucoisomerase（PGI） & 5.3 .1 .9 & $\mathrm{~S}_{6}$ & 1 \\
\hline 异柠檬酸脱氢酶 Isocitrate dehydrogenase（IDH） & 1.1 .1 .42 & $\mathrm{~W}_{2}$ & 3 \\
\hline 苹果酸脱氢酶 Malate dehydrogenase ( MDH) & 1.1 .1 .37 & $\mathrm{~W}_{2}$ & 5 \\
\hline 苹果酸酶 Malic enzyme（ME） & 1.1 .1 .40 & $\mathrm{~S}_{1}$ & 1 \\
\hline 维生素 $\mathrm{K}_{3}$ 还原酶 Menadione reductase (MNR) & 1.6 .99 .2 & $\mathrm{~W}_{2}$ & 3 \\
\hline 6-磷酸葡萄糖酸脱氢酶 6-Phosphogluconate dehydrogenase (PGD) & 3.4 .11 .1 & $\mathrm{~W}_{2}$ & 2 \\
\hline 磷酸葡萄糖变位酶 Phosphoglucomutase（PGM） & 5.4 .2 .2 & $\mathrm{~S}_{1}$ & 1 \\
\hline
\end{tabular}


(1965) 的固定指数 $F$ 对居群的异交率 $t$ 进行近似 估计 : $t=(1-F) /(1+F)$ (王崇云, 党承林, 1999)。 用 $\chi^{2}$ 检验每居群多态位点固定指数 $F$ 偏离 0 值的 程度（Wright,1965)。基因流（gene flow）采用居群 每代迁移数 $N m$ 来间接估计, $N m$ 采用 $F_{S T}$ 方法 $N m$ $=\left(1-F_{S T}\right) / 4 F_{S T}$ 计算 $($ Wright , 1951)。

\section{2 实验结果}

通过对 17 种酶系统的检测,获得 13 种酶系统 24 个位点的清晰且稳定的谱带 (表 1 ) ,其中 9 个位 点 (Adh、Amp-2、Dia-1、Gdh、Pgi、Mdh-1、Mdh-2、Me、
$M n r-2)$ 是单态的, 15 个位点为多态,Dia-2、Mdh-4 含 4 个等位基因, $M d h-3$ 含 5 个等位基因,其余多态位 点均含 2 个等位基因, 24 个位点共具有 46 个等位 基因 (见表 2 )。部分等位酶照片见图 2。

\section{1 等位基因频率}

在种水平上，等位基因频率不小于 0.60 的为常 见基因 (common alleles)，等位基因频率小于 0.05 的为稀有基因 (rare alleles)。由表 2“平均值”一栏 可看出，46 个等位基因中有 11 个稀有基因, 其中 3 个特有等位基因 (Dia- $\left.2^{a} 、 I d h-1^{b} 、 P g d-2^{b}\right)$ 仅分别出 现于 H2、H 5 以及 $\mathrm{H} 4$ 居群中。对于大多数多态位

表 210 个砂生槐居群在 15 个多态位点的等位基因频率

Table 2 Estimated allele frequencies at 15 polymorphic loci in the 10 populations of Sophora moorcroftiana

\begin{tabular}{|c|c|c|c|c|c|c|c|c|c|c|c|c|}
\hline \multirow{2}{*}{$\begin{array}{l}\text { 位点 } \\
\text { Locus }\end{array}$} & \multirow{2}{*}{$\begin{array}{c}\text { 等位基因 } \\
\text { Alleles }\end{array}$} & \multicolumn{11}{|c|}{ 居群 Population } \\
\hline & & H1 & $\mathrm{H} 2$ & $\mathrm{H} 31$ & $\mathrm{H} 32$ & $\mathrm{H} 4$ & H5 & H61 & H62 & $\mathrm{H} 7$ & $\mathrm{H} 8$ & $\begin{array}{c}\text { 平均值 } \\
\text { Mean }\end{array}$ \\
\hline \multirow[t]{2}{*}{ Aat } & $a$ & 0.563 & 0.184 & 0.038 & 0.038 & 0.000 & 0.000 & 0.000 & 0.000 & 0.000 & 0.000 & 0.082 \\
\hline & $b$ & 0.438 & 0.816 & 0.962 & 0.962 & 1.000 & 1.000 & 1.000 & 1.000 & 1.000 & 1.000 & 0.918 \\
\hline \multirow[t]{2}{*}{ Amp-1 } & $a$ & 0.000 & 0.000 & 0.338 & 0.100 & 0.213 & 0.538 & 0.000 & 0.275 & 0.138 & 0.125 & 0.173 \\
\hline & $b$ & 1. 000 & 1.000 & 0.663 & 0.900 & 0.788 & 0.463 & 1.000 & 0.725 & 0.863 & 0.875 & 0.827 \\
\hline \multirow[t]{4}{*}{ Dia-2 } & $a$ & 0.000 & 0.026 & 0.000 & 0.000 & 0.000 & 0.000 & 0.000 & 0.000 & 0.000 & 0.000 & 0.003 \\
\hline & $b$ & 0.500 & 0.487 & 0.500 & 0.500 & 0.500 & 0.500 & 0.500 & 0.500 & 0.500 & 0.500 & 0.499 \\
\hline & $c$ & 0.000 & 0.026 & 0.000 & 0.000 & 0.000 & 0.000 & 0.000 & 0.000 & 0.000 & 0.000 & 0.003 \\
\hline & $d$ & 0.500 & 0.461 & 0.500 & 0.500 & 0.500 & 0.500 & 0.500 & 0.500 & 0.500 & 0.500 & 0.496 \\
\hline \multirow[t]{2}{*}{ Fba } & $a$ & 0.988 & 1.000 & 1.000 & 0.975 & 1.000 & 1.000 & 1.000 & 1.000 & 0.962 & 1.000 & 0.992 \\
\hline & $b$ & 0.013 & 0.000 & 0.000 & 0.025 & 0.000 & 0.000 & 0.000 & 0.000 & 0.038 & 0.000 & 0.008 \\
\hline \multirow[t]{2}{*}{ Idh-I } & $a$ & 1. 000 & 1.000 & 1.000 & 1. 000 & 1.000 & 0.962 & 1.000 & 1.000 & 1. 000 & 1.000 & 0.996 \\
\hline & $b$ & 0.000 & 0.000 & 0.000 & 0.000 & 0.000 & 0.038 & 0.000 & 0.000 & 0.000 & 0.000 & 0.004 \\
\hline \multirow[t]{2}{*}{$I d h-2$} & $a$ & 0.300 & 0.474 & 0.463 & 0.225 & 0.650 & 0.575 & 0.262 & 0.300 & 0.175 & 0.350 & 0.377 \\
\hline & $b$ & 0.700 & 0.526 & 0.538 & 0.775 & 0.350 & 0.425 & 0.738 & 0.700 & 0.825 & 0.650 & 0.623 \\
\hline \multirow[t]{2}{*}{$I d h-3$} & $a$ & 1. 000 & 0.895 & 0.962 & 1. 000 & 0.975 & 1.000 & 1.000 & 1.000 & 1. 000 & 0.962 & 0.979 \\
\hline & $b$ & 0.000 & 0.105 & 0.038 & 0.000 & 0.025 & 0.000 & 0.000 & 0.000 & 0.000 & 0.038 & 0.021 \\
\hline \multirow[t]{5}{*}{$M d h-3$} & $a$ & 0.050 & 0.026 & 0.087 & 0.225 & 0.100 & 0.325 & 0.463 & 0.500 & 0.500 & 0.438 & 0.271 \\
\hline & $b$ & 0.025 & 0.132 & 0.013 & 0.025 & 0.050 & 0.025 & 0.000 & 0.000 & 0.000 & 0.000 & 0.017 \\
\hline & $c$ & 0.138 & 0.250 & 0.313 & 0.237 & 0.400 & 0.250 & 0.075 & 0.000 & 0.000 & 0.112 & 0.178 \\
\hline & $d$ & 0.063 & 0.355 & 0.237 & 0.138 & 0.125 & 0.200 & 0.438 & 0.500 & 0.500 & 0.375 & 0.293 \\
\hline & $e$ & 0.725 & 0.237 & 0.350 & 0.375 & 0.325 & 0.200 & 0.025 & 0.000 & 0.000 & 0.075 & 0.231 \\
\hline \multirow[t]{4}{*}{$M d h-4$} & $a$ & 0.025 & 0.053 & 0.013 & 0.025 & 0.038 & 0.013 & 0.000 & 0.000 & 0.000 & 0.000 & 0.017 \\
\hline & $b$ & 0.087 & 0.211 & 0.175 & 0.213 & 0.387 & 0.225 & 0.063 & 0.000 & 0.000 & 0.112 & 0.147 \\
\hline & $c$ & 0.100 & 0.461 & 0.313 & 0.225 & 0.162 & 0.350 & 0.850 & 1. 000 & 1. 000 & 0.750 & 0.521 \\
\hline & $d$ & 0.788 & 0.276 & 0.500 & 0.538 & 0.412 & 0.412 & 0.087 & 0.000 & 0.000 & 0.138 & 0.032 \\
\hline \multirow[t]{2}{*}{$M d h-5$} & $a$ & 1. 000 & 1.000 & 1.000 & 1. 000 & 1. 000 & 1.000 & 1.000 & 0.962 & 0.675 & 0.887 & 0.952 \\
\hline & $b$ & 0.000 & 0.000 & 0.000 & 0.000 & 0.000 & 0.000 & 0.000 & 0.038 & 0.325 & 0.112 & 0.048 \\
\hline \multirow[t]{2}{*}{ Mnr-l } & $a$ & 0.863 & 0.921 & 0.650 & 0.637 & 0.863 & 0.425 & 0.038 & 0.213 & 0.887 & 0.813 & 0.631 \\
\hline & $b$ & 0.138 & 0.079 & 0.350 & 0.363 & 0.138 & 0.575 & 0.962 & 0.788 & 0.112 & 0.188 & 0.369 \\
\hline \multirow[t]{2}{*}{ Mnr-3 } & $a$ & 1. 000 & 1.000 & 1.000 & 1. 000 & 1. 000 & 1.000 & 0.925 & 0.975 & 0.988 & 1.000 & 0.989 \\
\hline & $b$ & 0.000 & 0.000 & 0.000 & 0.000 & 0.000 & 0.000 & 0.075 & 0.025 & 0.013 & 0.000 & 0.011 \\
\hline \multirow[t]{2}{*}{$P g d-1$} & $a$ & 0.338 & 0.211 & 0.112 & 0.112 & 0.013 & 0.000 & 0.175 & 0.000 & 0.175 & 0.000 & 0.114 \\
\hline & $b$ & 0.663 & 0.789 & 0.887 & 0.887 & 0.988 & 1.000 & 0.825 & 1. 000 & 0.825 & 1.000 & 0.886 \\
\hline \multirow[t]{2}{*}{$P g d-2$} & $a$ & 1. 000 & 1. 000 & 1. 000 & 1. 000 & 0.988 & 1.000 & 1.000 & 1. 000 & 1.000 & 1.000 & 0.999 \\
\hline & $b$ & 0.000 & 0.000 & 0.000 & 0.000 & 0.013 & 0.000 & 0.000 & 0.000 & 0.000 & 0.000 & 0.001 \\
\hline \multirow[t]{2}{*}{$P g m$} & $a$ & 0.625 & 0.776 & 0.700 & 0.637 & 0.287 & 0.500 & 0.700 & 0.725 & 0.587 & 0.563 & 0.610 \\
\hline & $b$ & 0.375 & 0.224 & 0.300 & 0.363 & 0.712 & 0.500 & 0.300 & 0.275 & 0.412 & 0.438 & 0.390 \\
\hline
\end{tabular}



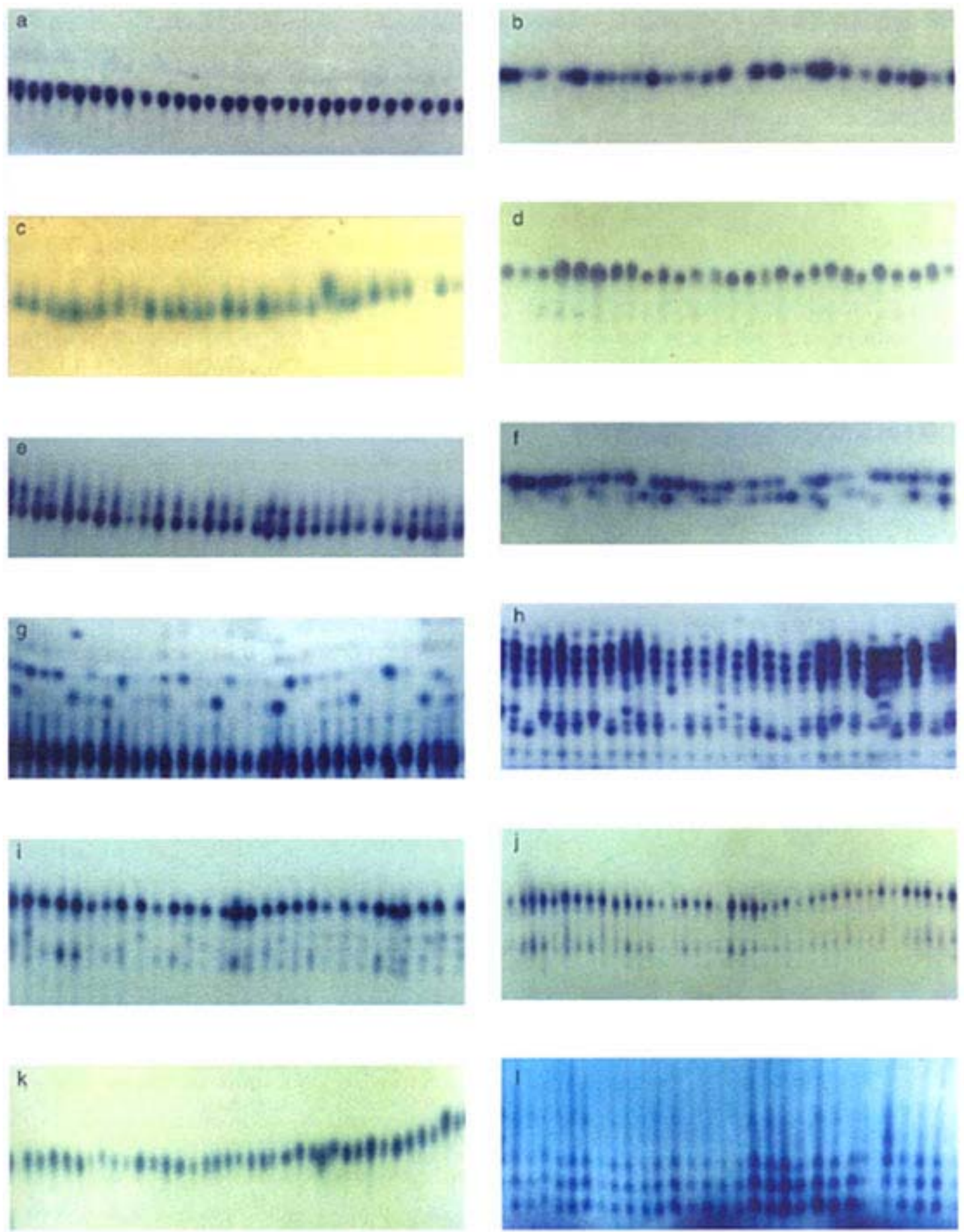

图 2 砂生槐部分等位酶照片

Fig.2 Gel pictures of Sophora moorcroftiana a, ME; b, ADH; c, AAT; d, AMP; e, PGD; f, PGM; g, MNR; h, MDH; i, IDH(群居 H31); j, IDH(群居 H7); k, PGI; 1, DIA 
点来说, 各居群通常共享常见基因, 而稀有基因通常 分布范围有限, 地方性稀有基因是居群为适应特定 的生态环境突变而产生的, 其存在反映了居群遗传 组成上的差异。

各居群的等位基因数存在较大差异, 其中居群 $\mathrm{H} 2$ 拥有最大等位基因数为 40 ,最小等位基因数为 32 ( H62) ,平均每居群等位基因数为 36.9 。居群 H1、H2、H31、H32、H4、H5 比居群 H61、H62、H7、H8 具较高的等位基因数, 这主要是由于 $M d h-3$ 和 $M d h-$ 4 位点的等位基因在较低海拔的 4 个居群 ( H61、 H62、H7、H8) 的特殊分布造成的: Mdh-3 位点具 5 个等位基因，后 4 个居群无 $b$ 等位基因, $c 、 e$ 基因频 率也均较少, 但 $d$ 基因频率明显较其他 6 个居群高， 尤其是 H62、H7 居群中等位基因 $a 、 d$ 为固定杂合状 态,而不具备 $c 、 e$ 基因。Mdh-4 位点的等位基因 $a$ 、 $b 、 d$ 分布类似于 $M d h-3$ 位点 $b 、 c 、 e$ 基因的分布。

\section{2 砂生槐天然居群的遗传多样性}

每个位点的平均等位基因数 $(A)$ 、多态位点百 分率 $(P)$ 以及平均观察杂合度 $\left(H_{o}\right)$ 和平均期望杂 合度 $\left(H_{e}\right)$ 是反映居群遗传多样性的常用指标。在 居群水平上砂生槐各居群的 $A_{p}$ 值非常接近 (1.3 $1.7)$,平均值为 1.5 ,居群 $\mathrm{H} 2$ 具有最大值 1.7 ,居群 $\mathrm{H} 62$ 具有最小值 $1.3 。 P_{p}$ 的平均值为 $31.7 \%$ $(25.0 \% \sim 37.5 \%), H_{o p}$ 和 $H_{e p}$ 的平均值分别为 0.142 $(0.110 \sim 0.176)$ 和 $0.143(0.112 \sim 0.169)$ 。居群 $\mathrm{H} 62$ 的 $P$ 值 $(25.0 \%)$ 最小, 该居群平均期望杂合度
$H_{e}(0.113)$ 也接近最低; 居群 $\mathrm{H} 2$ 的 $P$ 值 (37.5\%) 最大, 该居群平均期望杂合度 $H_{e}(0.159)$ 也较高。 在种水平上, 砂生槐的 $A_{s} 、 P_{s} 、 H_{o s} 、 H_{e s}$ 分别为 1.9 、 $37.5 \% 、 0.142 、 0.171$ ( 见表 3 )。

由对藏南砂生槐天然居群固定指数 $(F)$ 及其分 化程度的分析可知 (表 4 ) : 在 91 个检验中 (检验各 个居群各个多态位点的 $F$ 值),50 个符合 HardyWeinberg 平衡 $(P \geqslant 0.05) ; 41$ 个基因位点显著偏离 Hardy-Weinberg 平衡。所有居群平均固定指数 $F$ 为 $-0.184(-0.375 \sim 0.308)$, 很明显, 大部分居群均 呈现杂合子过量状态, 平均异交率 $t$ 较低( 0.770$)$, 变动幅度为 $0.529 \sim 0.949$ (见表 3 )。

\section{3 居群的遗传分化}

砂生槐 10 个居群 15 个多态位点的 $F$ 统计量分 解值和 $N m$ 值如表 5。 F 的平均值为 -0.0071 (位 点从 Dia-2 的 -0.9763 到 $I d h-3$ 的 0.5969），表明砂 生槐居群水平基因型偏离了 Hardy-Weinberg 平衡， 部分居群存在杂合子过量现象, 这也与表 3 中 $F$ 值 情况相符。 $F_{I T}$ 表示总居群中基因型的实际频率和 理论预期频率的离差, $F_{I T}$ 平均值为 0.1689 (从 $\mathrm{Dia}$ 2 的 -0.9752 到 $A a t$ 的 0.6817 ) 表明总居群纯合体 过量,杂合子严重不足。Dia-2、Fba、Idh-1、Mnr-3、 $P g d-1 、 P g d-2 、 P g m$ 位点的 $F_{I S}$ 和 $F_{I T}$ 均为负值,表明 这些位点上的杂合体比率大于期望值, 即居群中杂 合体过量的位点占全部位点的 $29 \%$ 左右。 $F_{S T}$ 用来 衡量亚居群之间的分化程度。砂生槐平均遗传分化

表 3 砂生槐 10 个居群遗传多样性 (括号内为标准误) 和固定指数 $(\boldsymbol{F})$ 、异交率 $(\boldsymbol{t})$

Table 3 Estimates of genetic variability at 24 loci in the 10 populations of Sophora moorcroftiana (standard errors in parentheses), and the value of fixation index $(F)$ and outcrossing rate $(t)$

\begin{tabular}{|c|c|c|c|c|c|c|c|c|}
\hline $\begin{array}{c}\text { 居群号 } \\
\text { Population No. }\end{array}$ & $\begin{array}{l}\text { 取样数 } \\
\text { Sample size }\end{array}$ & $\begin{array}{c}\text { 海拔 } \\
\text { Elevation }(\mathrm{m})\end{array}$ & $A$ & $P$ & $H_{o}$ & $H_{e}$ & $F$ & $t$ \\
\hline H1 & 40.0 & 4100 & $1.6(0.2)$ & 33.3 & $0.132(0.053)$ & $0.143(0.043)$ & 0.077 & 0.875 \\
\hline $\mathrm{H} 2$ & 38.0 & 3925 & $1.7(0.2)$ & 37.5 & $0.110(0.048)$ & $0.159(0.050)$ & 0.308 & 0.529 \\
\hline H31 & 40.0 & 3810 & $1.6(0.2)$ & 33.3 & $0.136(0.048)$ & $0.169(0.050)$ & 0.195 & 0.673 \\
\hline H32 & 40.0 & 3810 & $1.6(0.2)$ & 33.3 & $0.149(0.053)$ & $0.153(0.048)$ & 0.026 & 0.949 \\
\hline H4 & 40.0 & 3661 & $1.6(0.2)$ & 29.2 & $0.124(0.049)$ & $0.143(0.048)$ & 0.133 & 0.765 \\
\hline H5 & 40.0 & 3590 & $1.5(0.2)$ & 29.2 & $0.153(0.055)$ & $0.167(0.054)$ & 0.084 & 0.845 \\
\hline H61 & 40.0 & 3152 & $1.5(0.2)$ & 29.2 & $0.146(0.059)$ & $0.112(0.039)$ & -0.304 & - \\
\hline H62 & 40.0 & 3139 & $1.3(0.1)$ & 25.0 & $0.146(0.061)$ & $0.113(0.039)$ & -0.292 & - \\
\hline H7 & 40.0 & 2963 & $1.4(0.1)$ & 33.3 & $0.176(0.065)$ & $0.128(0.039)$ & -0.375 & - \\
\hline H8 & 40.0 & 2947 & $1.5(0.2)$ & 33.3 & $0.144(0.058)$ & $0.139(0.044)$ & -0.036 & - \\
\hline $\begin{array}{l}\text { 居群水平平均值 } \\
\text { Among-populations means }\end{array}$ & 39.8 & & $1.5(0.0)$ & 31.7 & $0.142(0.006)$ & $0.143(0.006)$ & -0.184 & 0.770 \\
\hline $\begin{array}{l}\text { 种水平值 } \\
\text { Species-level values }\end{array}$ & 398.0 & & $1.9(0.2)$ & 37.5 & $0.142(0.050)$ & $0.171(0.049)$ & - & - \\
\hline
\end{tabular}


表 4 每居群多态位点固定指数 $\boldsymbol{F}$ 值及 $\boldsymbol{\chi}^{2}$ 检验其偏离 0 值的程度

Table 4 Values of fixation index (inbreeding coefficient) $F$ for polymorphic loci in the 10 populations of Sophora moorcroftiana and its conformance to Hardy-Weinberg equilibrium ,i. e. statistical difference of $F$ values from zero, which was tested using chi-square analysis

注 Note :ns,$P \geqslant 0.05 ; * P<0.05 ; * * P<0.01 ; * * * P<0.001$.

居群编号见图 1。Abbreviations as in the legend to Fig. 1.

表 5 砂生槐居群分化的 $\boldsymbol{F}$-统计量分析和基因流

Table $5 \quad F$-statistics and gene flow in Sophora moorcroftiana

\begin{tabular}{|c|c|c|c|c|c|}
\hline $\begin{array}{l}\text { 位点 } \\
\text { Locus }\end{array}$ & $F_{I S}$ & $F_{I T}$ & $F_{S T}$ & $\begin{array}{l}\text { Heterogeneity of allele frequency } \\
\qquad \chi^{2}(\mathrm{P})\end{array}$ & $\begin{array}{l}\text { 基因流 } \\
\mathrm{Nm}\end{array}$ \\
\hline Aat & 0.4849 & 0.6817 & 0.3821 & $* * *$ & 0.4043 \\
\hline$A m p-1$ & 0.4165 & 0.5266 & 0.1887 & $* * *$ & 1.0749 \\
\hline Dia-2 & -0.9763 & -0.9752 & 0.0005 & $\mathrm{~ns}$ & 499.75 \\
\hline$F b a$ & -0.0300 & -0.0076 & 0.0218 & $*$ & 11.2179 \\
\hline Idh-1 & -0.0390 & -0.0038 & 0.0339 & $* *$ & 7. 1246 \\
\hline$I d h-2$ & 0.1262 & 0.2083 & 0.0939 & $* * *$ & 2.4124 \\
\hline$I d h-3$ & 0.5969 & 0.6173 & 0.0507 & $* * *$ & 4.6810 \\
\hline$M d h-3$ & 0.1379 & 0.2774 & 0.1618 & $* * *$ & 1.2951 \\
\hline$M d h-4$ & 0.4892 & 0.6440 & 0.3029 & $* * *$ & 0.5754 \\
\hline$M d h-5$ & 0.1557 & 0.3368 & 0.2145 & $* * *$ & 0.9155 \\
\hline$M n r-1$ & 0.1893 & 0.4883 & 0.3688 & $* * *$ & 0.4279 \\
\hline$M n r-3$ & -0.0604 & -0.0114 & 0.0462 & $* * *$ & 5.1613 \\
\hline$P g d-1$ & -0.2468 & -0.1024 & 0.1158 & $* * *$ & 1.9089 \\
\hline$P g d-2$ & -0.0126 & -0.0012 & 0.0113 & $\mathrm{~ns}$ & 21.8739 \\
\hline Pgm & -0.1456 & -0.0607 & 0.0741 & $* * *$ & 3.1238 \\
\hline $\begin{array}{l}\text { 平均值 } \\
\text { Mean }\end{array}$ & -0.0071 & 0.1689 & 0.1748 & $* * *$ & 1. 1802 \\
\hline
\end{tabular}

注:用 $\chi^{2}$ 检验 $F_{S T}$ 偏离 0 值程度 $: \mathrm{ns}, P \geqslant 0.05 ; * P<0.05 ; * * P<0.01 ; * * * P<0.001$.

Note : Values of $F_{S T}$ were tested for statistical difference from zero using contingency chi-square analysis as indicated by asterisks : ns , $P \geqslant 0.05 ; * P<$ $0.05 ; * * P<0.01 ; * * * P<0.001$.

度 $F_{S T}$ 为 0.1748 ,即总遗传变异的 $17.48 \%$ 来源于居 群间的遗传变异, $82.52 \%$ 属于居群内的遗传变异。 除位点Dia-2、Pgd-2 外, 其余位点的 $F_{S T}$ 值都显著偏 离 0 值。

\section{3 讨论}

\section{1 砂生槐的遗传多样性}

一般而言, 稀有种或特有种以及分布范围狭窄 
的植物种与分布范围广的物种相比, 遗传多样性水 平较低( Hamrick \& Godt ,1989) ,对砂生槐的遗传多 样性水平的研究亦证明了这一点。砂生槐的遗传多 样性在种水平上 $\left(P_{s}=37.5 \%, A_{s}=1.9, H_{e s}=\right.$ $0.171)$ 和居群水平上 $\left(P_{p}=31.7 \%, A_{p}=1.5, H_{e p}=\right.$ $0.143)$ 均明显低于长寿命木本被子植物的平均值 $\left(P_{s}=59.5 \%, A_{s}=2.10, H_{e s}=0.183\right) 、\left(P_{p}=45\right.$. $1 \%, A_{p}=1.68, H_{e p}=0.143$ ) ( Hamrick \& Loveless ， 1992 )。由此可见, 砂生槐具较低的遗传变异水平。

Hamrick \& Godt (1989) 认为, 影响居群遗传变 异大小的主要因素依次为繁育系统 $(33 \%)$ 、分布范 围 (28\%) 和习性 (12\%)。砂生槐为典型的豆科蝶 形花,豆科植物以其特殊的花结构保证自花受粉，同 时蝶形花冠也是进一步向虫媒方向演化的结果 (吴 国芳等,1983)。从砂生槐的居群的平均固定指数 可以看出, $F$ 值 $(-0.184)$ 为负值, 且偏离 0 值的程 度较大, 说明杂合子过量, 存在不同程度的异交, 异 交率 $(t)$ 在 $0.529 \sim 0.949$ 之间变化, 表明砂生槐兼 备自花受粉与虫媒传粉的混合交配系统。此外, 砂 生槐的繁殖方式还有其特殊性 :即未受沙埋时, 种子 繁殖占主导地位;而在生境受到沙埋时，以营养繁殖 为主(赵文智,刘志民，2002）。砂生槐遗传多样性 水平较低主要有几个方面的原因: (1) 它是虫媒混 交植物, 且兼备有性和无性两种繁殖方式,异交率 低,且无性繁殖也可导致基因重组率降低;(2) 它是 青藏高原特有种, 分布区狭小, 可能在进化历史上经 历过严重的瓶颈 (bottleneck) 作用; (3) 它是半固定 沙地的先锋灌丛植物, 靠种子迁徙侵入, 在生态群落 中处于演替阶段早期（刘志民，2001）,易受奠基者 效应 ( founder effect) 的影响。

\section{2 砂生槐的遗传分化}

$G_{S T}$ 等于所有位点 $F_{S T}$ 的加权平均值 ( Khasa et al. , 1994) ,所以砂生槐居群间的遗传分化 $\left(F_{S T}=\right.$ $0.1748)$ 能与以 $G_{S T}$ 作为遗传分化衡量指标的其他 植物种相比较。根据 Hamrick \& Loveless (1992) 分 类总结的多年生木本植物的 $G_{S T}$ 值, 特有植物种 $G_{S T}$ $=0.141( \pm 0.049) 、$ 自交兼虫媒植物种 $G_{S T}=0.122$ $( \pm 0.038)$ 、异交虫媒植物种 $G_{S T}=0.099( \pm$ $0.017)$ 、有性兼无性繁殖植物种 $G_{S T}=0.051( \pm$ $0.013)$ 。与上述 $G_{S T}$ 值相比, 砂生槐居群间遗传分化 系数 $\left(F_{S T}=0.1748\right)$ 较大。Ellstand \& Elam (1993) 认为, $G_{S T}>0.1$ 意味着居群间变异程度较高, 砂生
槐的 $F_{S T}=0.1748>0.1$, 表明砂生槐是居群间分化 较大的一类多年生木本植物。

影响居群遗传结构的因素除繁育系统、分布范 围外,基因流也是一个重要因素。据 Slatkin (1985) 和 Hamrick et al. (1995) 的观点, 若每代迁入个体 数 $N m>1$,基因流就足以抵制遗传漂变的作用，同 时也可以防止种群分化的发生; 若 $N m<1$, 漂变就 成为刻划种群遗传结构的主导因素。砂生槐总居群 的 $N m=1.1802 \approx 1$ (表 5 ) ,表明砂生槐天然居群正 处于分化的临界状态。目前由于环境恶化和人类活 动干扰 (过度砍伐、放牧) 等导致砂生槐生境片断 化, 影响居群间基因交流，正是加大居群间遗传分化 的主要原因。另一方面,地理因素如海拔高度对温 度、水分等生态因子有着规律性影响，从而控制了居 群分化。海拔高度不同的砂生槐亚居群, 开花物候 期不同，这就造成了由于传粉不同步而造成的遗传 隔离。

目前,由于过度放牧与樵采, 造成植被严重破 坏，砂生槐作为一种非常有前途的固沙植物种，其基 因资源的保护问题已迫在眉睫。遗传多样性的研究 为砂生槐资源保护提供了依据:砂生槐遗传变异主 要保持在居群内, 在迁地保护时要选择有代表性的 几个居群，每个居群多取样; 居群 H2、H31、H32、H5 遗传多样性水平较其他居群高，且含有绝大多数等 位基因，对该 4 个居群所在区域加以重点保护可收 到事半功倍的效果。

致谢 :非常感谢葛颂博士、曾杰博士和李斌博士在数 据处理和论文修改过程中的指导和帮助。

\section{参考文献}

Barrett S. C. H. and Koho J. R. 1991. Genetic and evolutionary consequences of small population. In: Falk D. A. and Holsinger K. E. ( eds.), Genetics and Conservation of Rare Plants. Oxford University Press, New York, 3 - 30.

Ellstrand N. C. and Elam D. R. 1993. Population genetic consequences of small population size: implications for plant conservation. Annual Review of Ecology and Systematics, 24: $217-242$.

Ge S, Zhang D-M, Wang H-Q and Rao G-Y. 1997. Allozyme variation in Ophiopogon xylorrhizus, an extreme endemic species of Yunnan, China. Conservation Biology, 11(2): $562-565$.

Hamrick J. L. and Godt M. J. W. 1989. Allozyme diversity in plant species. In: Brown A. D. H., Clegg M. T., Kahler 
A. L. and Weir B. S. (eds.), Plant Population Genetics, Breeding and Genetics Resources. Sinauer, Sunderland, 43 -63 .

Hamrick J. L. and Godt M. J. W. 1996. Conservation genetics of endemic plant species. In: Avise J. and Hamrick J. L. (eds.), Conservation Genetics: Case Histories from Nature. Chapman and Hall, London, UK, 281 - 304.

Hamrick J. L. and Loveless M. D. 1992. Factors influencing levels of genetic diversity in woody plant species. New Forests, 6: $95-124$.

Hamrick J. L., Godt M. J. W. and Sherman-Broyles L. S. 1995. Gene flow among plant populations: evidence from genetic markers. In: Hoch D. C. and Stephnon A. G. (eds.), Experimental and Molecular Approaches to Plant Biosystematics. Missouri Botanical Garden, St. Louis, 215 -232 .

Holsinger K. E. and Gottlieb L. D. 1991. Conservation of rare and endangered plants: principles and prospects. In: Falk D. A. and Holsinger K. E. (eds.), Genetics and Conservation of Rare Plants. Oxford University Press, New York, USA, $195-208$.

Ji W-Z (季维智) and Su B. (宿兵) (主编). 1998. Principles and Methodologies of Genetic Diversity Studies (遗传多样性 研究的原理与方法). Zhejiang Science and Technology Press, Hangzhou. (in Chinese)

Khasa P. D., Cheliak W. M. and Bousqvet J. 1994. Genetic variation in 26 populations of Racosperma auriculiforme and Racosperma mangium using allozymes. Canadian Journal of Forest Research, 24: 1123 - 1132.

Liu Z-M (刘志民)，Zhao W-Z (赵文智) and Li Z-G (李志 刚). 2002. Characteristics of the seed bank of Sophora moorcroftiana population in the middle reach of Yarlung Zangbo River, Tibet. Acta Ecologica Sinica (生态学报), 22(5) : 715 - 722. (in Chinese)

Slatkin M. 1985. Rare alleles as indicators of gene flow. Evolution, 39: $52-65$.

Soltis D. E. and Rieseberg L. H. 1986. Autopolyploidy in Tolmiea menziesii: genetic insights from enzyme electrophoresis. American Journal of Botany, 73: 310 - 318 .

Soltis D. E., Haufler C. H., Darrow D. C. and Gastony G. J. 1983. Starch gel electrophoresis of ferns: a compilation of buffers, gel and electrode buffers, and staining schedules. American Fern Journal, 73: 9 - 27.

Swoffod D. L. and Selander R. B. 1989. BIOSYS- I, A computer program for the analysis of allelic variation in population genetics and biochemical systematics, release 1. 7 .
Illinois Natural History Survey, Champain, Illinosis.

W ang C-Y (王崇云) and Dang C-L (党承林)。1999. Plant mating system and its evolutionary mechanism in relation to population adaptation. Journal of Wuhan Botanical Research (武汉植物学研究), 17(2)：163-172. ( in Chinese)

Wang S-M (王善敏) and Liu Y-H (刘玉红) and Xu Y-Y (许 毓英). 1995. The Karyotype analysis of Sophora moorcroftiana in Tibet, China. Grassland of China (中国 草地), 4: 49 - 51. (in Chinese)

Wang W-Y (王为义). 1980. Observation on the capacity of drought resistance of Sophora moorcroftiana (Wall.) Benth. Ex Baker. Acta Botanica Sinica (植物学报), 22 (3) : 293 - 294. ( in Chinese)

Wang Z-R (王中仁). 1996. Plant Allozyme Analysis (植物等 位酶分析). Science Press, Beijing, $74-163$. ( in Chinese)

Wendel J. F. and Weeden N. F. 1989. Visualization and interpretation of plant isozymes. In: Soltis D. E. and Solis P. S. (eds.), Isozymes in Plant Biology. Dioscorides Press, Portland, Oregon, 5-45.

Wright S. 1951. The genetical structure of populations. Annals of Eugenetics, 15: 323 - 354 .

Wright S. 1965. The interpretation of population structure by $F$ statistics with special regard to systems of mating. Evolution, 19: $395-420$.

Wright S. 1978. Evolution and the Genetics of Populations. Vol. 4. Variability within and among Natural Populations. University of Chicago Press, Chicago

Wu G-F (吴国芳) and Feng Z-J (冯志坚), and Ma W-L (马 炜梁). 1983. Botany (2nd edn.) [ 植物学(第二版)]. Higher Education Press, Beijing, 272. (in Chinese)

Zhao W-Z (赵文智). 1998. A preliminary study on the arenaceous adaptability of Sophora moorcroftiana. Acta Phytoecologica Sinica (植物生态学报), 22 (4): 379-384. (in Chinese)

Zhao W-Z (赵文智) and Liu Z-M (刘志民). 2002. Response of growth and reproduction of Sophora moorcroftiana to altitude and sand-burying in Tibet. Acta Ecologica Sinica (生 态学报), 22(1): 134 - 138. (in Chinese)

Zhou S-L (周世良), Zhang F (张方), Wang Z-R (王中仁). 1998. Some advises for starch gel electrophoresis in allozyme analysis. Chinese Bulletin of Botany (植物学通报), 15(5): 68 - 72. (in Chinese)

(责任编辑：时意专) 